\title{
Espaço, Localização e Lugar na teoria de Milton Santos
}

\section{Space, Location, and Place in Milton Santos theory}

\section{Espacio, Ubicación y Lugar en la teoría de Milton Santos}

\author{
Cilene Gomes \\ http:/ / orcid.org/0000-0001-5217-9426 \\ cilenegs@univap.br \\ Universidade do Vale do Paraíba, UNIVAP, São José dos Campos, SP
}

\begin{abstract}
Resumo: Esse ensaio centra-se no estudo da articulação conceitual entre espaço, localização e lugar, com base na teoria do espaço do renomado geógrafo brasileiro Milton Santos, e destaca o papel atribuído à Geografia em sua condição disciplinar de ciência humana e de atuação prática contributiva da planificação. Este papel se exerce mediante a construção de uma visão abrangente do presente, dos estados de crise social, e delineamentos de ação política e projetos de futuro. A prevalência do interesse social seria advinda da desalienação epistemológica, da mudança do Estado e da força emergente dos cidadãos, confluindo à proposição de uma redistribuição espacial mais equitativa dos recursos sociais.
\end{abstract}

Palavras-chave: Geografia, Redistribuição espacial, Ação política.

Abstract: This essay focuses on the study of the conceptual articulation between space, location, and place, based on the space theory of the renowned Brazilian geographer Milton Santos, and highlights the role attributed to Geography in its disciplinary condition of human science and practical action in contributing to planning. This role is exercised through the construction of a comprehensive view of the present, of the states of social crisis, and delineations of political action and future projects. The prevalence of social interest would be due to epistemological disalienation, state change, and the emerging strength of citizens, contributing to the proposition of a more equitable spatial redistribution of social resources.

Keywords: Geography, Spatial redistribution, Political action.

Resumen: Este ensayo se centra en el estudio de la articulación conceptual entre espacio, ubicación y lugar, basada en la teoría del espacio de este reconocido geógrafo brasileño Milton Santos, y destaca el papel atribuido a la Geografía, en su condición disciplinaria de la ciencia humana y la acción práctica contribuyente de la planificación. Lo que se ejerce al construir una visión integral del presente y los estados de crisis social, y esquemas de acción política y proyectos futuros, cuya prevalencia de interés social provendría de la dislocación epistemológica, el cambio de estado y la fuerza emergente de ciudadanos que convergen en la propuesta de una redistribución espacial más equitativa de los recursos sociales.

Palabras clave: Geografía, Redistribución espacial, Acción política. 


\section{INTRODUÇÃO}

Este ensaio de natureza conceitual resultou de um convite para desenvolvimento de um dos pontos que constituem o manifesto intitulado O Papel Ativo da Geografia (Santos et al., 2000), proposto por Milton Santos e apresentado inicialmente no XII Encontro Nacional de Geógrafos, realizado em Florianópolis em 2000, publicado em diferentes periódicos especializados e, recentemente, publicado em língua inglesa na revista Antípode (Santos et al., 2017). O primeiro ponto do Manifesto, abaixo transcrito, foi o escolhido para o referido exercício de desenvolvimento.

O papel atribuído à geografia e a possibilidade de uma intervenção válida dos geógrafos no processo de transformação da sociedade são interdependentes e decorrem da maneira como conceituamos a disciplina e seu objeto.

Se tal conceituação não é abrangente de todas as formas de relação da sociedade com seu meio, as intervenções serão apenas parciais ou funcionais, e sua eficácia será limitada no tempo.

É verdade que, na linguagem comum e no entendimento de outros especialistas, assim como de políticos e administradores, a geografia é frequentemente considerada como a disciplina que se preocupa com localizações. Aliás, um bom número de geógrafos trabalha com essa visão.

A geografia considerada como disciplina das localizações, posição aceita durante largo tempo, mostra-se, todavia, limitante do rol de relações que se dão entre o homem e o meio e, por essa razão, revela-se insuficiente.

Mas esse não é o único enfoque simplificador e deformador. (Santos et al., 2000, p. 1)

\section{DESENVOLVIMENTO}

Com base na releitura de alguns tópicos de livros de Milton Santos, entende-se que a validade da proposição geográfica no processo de transformação da sociedade reside, primordialmente, na coerência à sua fundamentação: na conceituação da natureza do espaço e no método de estudo da sociedade pela categoria espaço.

Além disso, nas situações em que os geógrafos são chamados a participar, espera-se que a Geografia professe uma preocupação com o futuro do homem - o homem enquanto projeto. Não por mero exercício acadêmico, mas por um compromisso social, a geografia tem que ser reformulada para ser uma ciência do homem. Em função do conhecimento do espaço e da prevalência do interesse social, a geografia deve colaborar para "dominar o futuro para o Homem" (Santos, 1980, p. 213), a ponto de influenciá-lo "para todos os homens e não só para um pequeno número deles" (Santos, 1980, p. 213). Trabalhar com firmeza de propósito para não alimentar processos de subjugação, dependências e segregações.

Em seu livro Espaço e Método, na versão em francês, Santos (1989, pp. 5-8) define o objeto da Geografia: o espaço humano em sua totalidade e essência social. O espaço é uma instância da sociedade, que contém e é contida pelas demais instâncias sociais - a instância 
econômico-produtiva, a político-institucional e a ideológico-cultural. Além disso, não é simples condição, mas fator da evolução social.

Assim entendendo o espaço, o autor não o concebe limitado à repartição dos "objetos geográficos naturais e artificiais" sobre o território, mas, sim, em consideração ao seu princípio ativo: "todos os processos sociais que exprimem uma sociedade em dado momento" e "se realizam em funções através de formas". Desse modo, define-se sua noção de formas-conteúdo de frações do social, formas sociais que adquirem expressão territorial e novos significados ao longo do tempo. Daí o movimento dialético entre forma e conteúdo que o espaço preside: “A ação, inerente à função, se une com a forma que a acolhe, e assim os processos encontram sua plena significação quando tomam corpo" (Santos, 1989, p. 6).

Com essa conceituação abrangente do objeto disciplinar, o autor não concebe a Geografia enquanto ciência das localizações, justamente pela delimitação restrita da ciência geográfica se considerasse a localização (em si) como foco da investigação. Todavia, as localizações do espaço também fazem parte dos questionamentos do geógrafo: "O que caracteriza a análise do espaço? Como passar do sistema produtivo ao espaço? Como dar conta da questão da periodização, da difusão de variáveis e da significação das localizações"? (Santos, 1989, p. 5).

Se na prática da análise, é preciso dividir o objeto do conhecimento em partes, vale indagar se as localizações são equiparáveis a elementos da análise geográfica; se poderíamos a partir delas operacionalizar a reconstituição do espaço-tempo social em seu todo.

Para Santos:

cada localização é (...) um momento do imenso movimento do mundo, contido em um ponto geográfico, um lugar. E é por causa desse movimento social que cada lugar muda sem cessar de significação: a cada instante as frações da sociedade que o concernem, não são as mesmas. Localização e lugar são, portanto, duas coisas distintas. O lugar pode permanecer o mesmo enquanto que as localizações mudam. O lugar é um objeto ou um conjunto de objetos. A localização é um feixe de forças sociais convergentes em um lugar. (Santos, 1989, pp. 6-7)

Acompanhando sua teorização sobre os eventos, em seu livro A Natureza do Espaço (Santos, 1996, pp. 114-126), poder-se-ia pensar em alguma possível correlação conceitual entre localização e evento, quando se considera que "a conexão existente entre os objetos é dada pelos eventos, isto é, o tempo se fazendo empírico, para poder encontrar os objetos" (Santos, 1996, p. 126) no lugar preciso em que se encontram. Diz o autor: se "um evento não é o equivalente de localização (...), o conteúdo das diversas áreas tem o que ver com a natureza dos eventos que nela se estendem" (Santos, 1996, p. 120).

O fato é que Milton Santos termina, ele mesmo, por nos orientar na busca de entendimento de suas formulações, ao perguntar: "Que forças são capazes de produzir eventos que incidam, num mesmo momento, sobre áreas extensas?" (Santos, 1996, p. 121).

Ou seja, as forças sociais produzem eventos que, sendo sinônimo de ações (Santos, 1996, p. 117), "são, simultaneamente, a matriz do tempo e do espaço (...) um instante do tempo dando-se em um ponto do espaço" (Santos, 1996, p. 115). Sendo assim, subentende-se 
que a localização é o lugar da confluência de forças sociais - forças afins ao valor diferencial do lugar - que assumem a forma de ações criadoras do acontecer presente; ações condicionadas pela estrutura de objetos existentes no lugar e, portanto, ações somente existentes de modo interdependente a estes objetos.

Nesse sentido, se "cada ação se dá segundo seu tempo; as diversas ações se dão conjuntamente", sendo, de fato, "a simultaneidade das diversas temporalidades sobre um pedaço da crosta da Terra (...) que constitui o domínio propriamente dito da Geografia". Em suas palavras: "pergunta-se se o estudo geográfico não é muito mais essa outra forma de ver o tempo como simultaneidade" (Santos, 1996, p. 127), e neste mesmo livro, recorda que, nas palavras de Sartre, "os fatos não são aparições isoladas, eles se produzem conjuntamente na unidade superior de um todo" (Santos, 1996, p. 129). Ou seja, assim como "os eventos [que] não se dão isoladamente, mas em conjuntos sistêmicos" (Santos, 1996, p. 119), profundamente imbricados na globalidade do espaço-tempo, em sua universalidade.

Outra acepção para as localizações que se depreende da obra do geógrafo combina-se com o enunciado do princípio da seletividade espacial. Ao discorrer sobre uma "economia política do território", em seu livro O Brasil, Santos (2001, p. 302) afirma, em co-autoria com Maria Laura Silveira, que "o neoliberalismo conduz a uma seletividade maior na distribuição geográfica dos provedores de bens e de serviços, levados pelo império da competitividade a buscar, sob pena de seu próprio enfraquecimento, as localizações mais favoráveis (...) punindo, assim, as populações mais pobres, mais isoladas, mais dispersas e mais distantes dos grandes centros e dos centros produtivos".

Nesse processo em que "a localização de fixos subordina-se à lei do lucro, muito mais que à eficiência social" (Santos, 1987, p. 115), no livro O Espaço do Cidadão, o autor atribui à "má organização do território pelo poder público" o fato deste também colaborar "para a supervalorização de certas áreas, para o melhor êxito da especulação, para a maior anarquia das localizações e dos fluxos, para o empobrecimento cumulativo das populações" (Santos, 1987, p. 115). Acrescenta também que a própria "localização das pessoas no território é, na maioria das vezes, produto de uma combinação entre forças de mercado e decisões de governo", independente, portanto, da vontade dos indivíduos (Santos, 1987, p. 112).

Essa seria a lógica prevalecente da localização que insere diferencialmente os lugares no processo produtivo em função das condições de cada lugar para realizações específicas. Por essa razão, tal lógica estabelece a hierarquia entre os lugares, quando os atributos do lugar melhor correspondem aos fins esperados no contexto das atividades de concepção (pesquisa), controle, coordenação e previsão. Nas dinâmicas atuais de globalização, a autonomia dos lugares nessas atividades se torna hoje essencial (Santos, 1989, pp. 7-8).

Por aí se entende a relação permanentemente instável, a que se refere Milton Santos, "onde globalização e localização, globalização e fragmentação são termos de uma dialética refeita com frequência". Pois, se "cada lugar é, à sua maneira, o mundo" (Santos, 1996, p. 252), sendo "ao mesmo tempo, objeto de uma razão global e de uma razão local, convivendo dialeticamente" (Santos, 1996, p. 273), "para apreender essa nova realidade 
do lugar, não basta adotar um tratamento localista, já que o mundo se encontra em toda parte" (Santos, 1996, p. 252).

De outro lado, se "nossa relação com o mundo é agora local-global" e "a dimensão local é redescoberta", a questão do lugar é reposta, em nosso tempo, em uma posição central. Para Santos tal fato exige que o lugar seja revisitado e resignificado. Nesse esforço, o cotidiano imediato, localmente vivido, é o traço de união da ordem local ou do espaço banal ao espaço movediço formado de pontos, dos lugares articulados em redes, da ordem global, "que separa o centro da ação e a sede da ação" (Santos, 1996, pp. 272-273).

Ora, se os lugares possuem valores diferenciais e "o valor do indivíduo depende, em larga escala, do lugar onde está" (Santos, 1987, p. 111), eis um enunciado para repensar, à luz da proposição de Milton Santos, "as bases de reconstrução de um espaço geográfico que seja realmente o espaço do homem, o espaço de toda gente" (Santos, 1980, p. 219). Onde a centralidade deverá estar no homem, na restauração da sua dignidade e em sua libertação, "como um dado filosófico e como uma inspiração para as ações" (Santos, 2000a, p. 147).

Não por menos, diz Milton Santos: "é preciso coragem no estudo e na ação" para essa tarefa de fôlego. Para discernir o invisível além da forma e da aparência, que termina sendo o mais fundamental na busca de explicação do espaço e da sociedade; para tentar "distinguir aquilo que faz do espaço não a morada do homem, mas sua prisão" (Santos, 1980, p. 216). "Para chegar a esse resultado, somente a compreensão da coisa geográfica, tanto no seu valor profundo, como na finalidade última a que se destina, pode ser de algum auxílio. E por isso não pode ser feito sem ultrapassar o empírico para alcançar o filosófico" (Santos, 1980, p. 219).

Imbuindo-se do chamado de Milton Santos "por uma geografia liberada" (Santos, 1980, pp. 214-215 e p. 219), deveríamos nos perguntar em que medida o interesse social preside realmente a construção de nosso conhecimento, para não se incorrer no engano de "uma alienação epistemológica". Colaboramos para denunciar as mistificações de um "saber ideológico" que termina por compactuar com um problema que não é só do conhecimento, mas é também um problema moral? A serviço de que projeto os agentes do conhecimento do espaço humano ainda trabalham para o entorpecimento da humanidade e sua escravidão?

Quais os fundamentos e propósitos da geografia de Milton Santos para orientar a formulação de novos desígnios de intervenção territorial por via da planificação? Certamente, tais embasamentos dizem respeito a uma visão teórica abrangente e substantiva, contrária à universalidade parcial do sistema social de privilégios de alguns privilegiados (Santos, 1980, p. 214) no exercício de sua força de dominação ou poder econômico. A geografia de Milton Santos incentiva, assim, a vigilância permanente na busca de promover a elucidação dos estados de crise social (Santos, 1980, p. 93), para o ajustamento de novos princípios e caminhos da ação que possam conduzir a uma redistribuição socioespacial equitativa (Santos, 1987, p. 115).

Para isso, seria preciso pensar mais em termos de contexto do que de causas e efeitos, e assim, não concebendo uma geografia aos pedaços, "reconhecer o valor de cada coisa no interior da totalidade" (Santos, 1980, pp. 214-215). O geógrafo considera que "como o que 
acontece num lugar influi sobre todos os demais, como a totalidade dos lugares interage, o melhor, ainda uma vez, é agir sobre o que age sobre a totalidade dos lugares, isto é, a própria sociedade considerada como um todo" (Santos, 1980, p. 111).

E aqui, para não descaracterizar seu enfoque totalizante de uma realidade complexa (como a que envolve todas as formas de relação da sociedade com seu meio), a questão da transformação social, no contexto da formação espacial brasileira e do dever político constitucional, equaciona-se, estruturalmente, e em distintas escalas de tempo, tanto pela ação do Estado como por emergência gradual da força dos cidadãos (Santos, 1987; Santos, 2000a).

Enunciando sua aspiração por "uma nova federação" dos lugares, Santos (2000b) propõe a ideia de "uma política efetivamente redistributiva visando a que as pessoas não sejam discriminadas em função do lugar onde vivem" e de "autêntica instrumentação do território que a todos atribua, como direito indiscutível, todas aquelas prestações sociais indispensáveis a uma vida decente" (Santos, 1987, p. 113). Política esta que somente terá seu escopo completo com a força centrípeta da cidadania "capaz de estar presente em todos os lugares onde se exerce" e de "facilitar a eclosão da vontade de entendimento das situações e de ampliação da consciência" (Santos, 2001, pp. 305-306).

Nesse sentido, o conhecimento é considerado um bem público essencial a ser buscado junto com a própria felicidade, um dado a ser constantemente considerado nos eventos criados pela política, "porque em um mundo desprovido da vontade e vocação para a felicidade, o progresso do conhecimento não tem nenhum objetivo" (Santos, 1980, p. 214).

Com a esperança de que a ciência geográfica possa sempre se desenvolver com a perspectiva da reconstrução de um saber novo e uma ação nova (Santos, 1980), eis um evento de minha memória de Milton Santos: do pouco que pude agora reavivar do muito que me ensinou e continua ensinando em sua teoria.

\section{CONSIDERAÇÃO FINAL}

A pesquisa conceitual na obra de Milton Santos é um exercício muito profícuo para a fundamentação teórica em Geografia ou no campo dos Estudos Urbanos e Regionais, exercício este, que não se dissocia da compreensão do método histórico-crítico e dialético com que o geógrafo desenvolveu suas pesquisas, análises e elaborações teóricas. Na construção do método e por meio dele, propõe a sua teoria geográfica distinguindo o papel da Geografia diante do desafio de pensar o futuro do homem a partir da desalienação epistemológica, de análise do presente e dos estados de crise social e, ainda, do delineamento de um projeto político que considera a possibilidade de mudança da ação do Estado e da força emergente dos cidadãos (sobre o imperativo tecnológico) (Santos, 1979) confluindo no sentido de uma redistribuição socioespacial mais equitativa dos recursos sociais. 


\section{REFERÊNCIAS}

Santos, M. (1979). Espaço e sociedade (2a ed.). Petrópolis: Vozes.

Santos, M. (1980). Por uma geografia nova: da crítica da geografia a uma geografia crítica. São Paulo: HUCITEC.

Santos, M. (1987). O espaço do cidadão. São Paulo: Nobel.

Santos, M. (1989). Espace et méthode. Paris: PubliSud.

Santos, M. (1996). A natureza do espaço: técnica e tempo, razão e emoção. São Paulo: HUCITEC.

Santos, M., Bernardes, A., Gomes, C., Bicudo, E., Almeida, E., Contel, F. B., ... Belo, V. L. (2000, julho). O papel ativo da geografia: um manifesto. Encontro Nacional de Geógrafos, Florianópolis, SC, Brasil, 12. Recuperado de http://miltonsantos.com.br/site/wp-content/uploads/2011/08/O-papel-ativo-dageografia-um-manifesto_MiltonSantos-outros_julho2000.pdf

Santos, M. (2000a). Por uma outra globalização: do pensamento único à consciência universal. Rio de Janeiro: Record.

Santos, M. (2000b). Por uma nova federação. Brasília: Correio Braziliense.

Santos, M., \& Silveira, M. L. (2001). O Brasil: território e sociedade no início do século XXI. Rio de Janeiro: Record.

Santos, M., Bernardes, A., Gomes, C., Bicudo, E., Almeida, E., Contel, F. B., ... Belo, V. L. (2017). The Active Role of Geography: A Manifesto. Antipode, 49, 952-958. doi: doi.org/10.1111/anti.12318.

Data de submissão: 03/jun./2020

Data de aceite: 20/jun./2020 